\title{
LEANDRO FERNÁNDEZ DE MORATÍN Y JOSÉ DE LUGO EN LONDRES (1792-1793)
}

Jorge DEMERSON

Sabido es que José de Lugo hizo dos viajes a América del Norte, el primero antes del nacimiento de los Estados Unidos, en 1777, y el segundo en 1784-1785 (Demerson, 1988a, págs. 13-16).

Antes de realizar estos viajes, había estado en Inglaterra para aprender el inglés y conocer la vida y costumbres de los insulares.

A la vuelta de su segundo viaje a América, tras de permanecer una temporada en su patria chica, Tenerife, Lugo pasó de nuevo a Gran Bretaña en 1788. En ese país, como ya lo había hecho allí y en otras partes, trató de fomentar el comercio de los vinos de su tierra. Pero no se limitó al papel de corredor, activo por cierto, de los viticultores y vinateros de Canarias. Tenía más ambición. Procuró y consiguió que las autoridades inglesas modificasen la legislación aduanera de su país, poco favorable entonces a la importación de este artículo, cuya venta era recurso imprescindible para la economía del archipiélago guanche. Gracias a sus gestiones pacientes y tozudas, obtuvo del gobierno británico un decreto permitiendo que los vinos de Canarias pudiesen ir en derechura desde aquellas islas a la Jamaica y demás establecimientos ingleses de Asia, Africa y América: ventaja considerable, que favorecía notablemente la agricultura y el comercio canario.

Al defender y dar a conocer los productos de su tierra natal, Lugo actuaba "por puro efecto de su patriotismo", ya que no cobraba nada. Dijo más tarde que en esas campañas de promoción, gastó todo su patrimonio. Pero esa abnegación generosa y desinteresada no tardó en recibir la recompensa que se merecía. En efecto, en enero de 1793, sus coterráneos, a través del Consulado de Canarias, acordaron expresarle oficialmente su reconocimiento "por los 
beneficios que su patriotismo había procurado con el mayor desinterés al comercio de las islas, autorizándole con poder bastante para que en nombre de dicho Consulado promoviese y adelantase las demás pretensiones que tenía pendientes en la Corte de Londres". Acordó asimismo el Consulado "recomendarle a la piedad del Rey y solicitar su Real aprobación para recompensarle debidamente por los importantes servicios que había hecho, tanto más apreciables cuanto que habían sido practicados oficiosamente por el solo impulso del honor y del amor a la Patria" (ibíd., pág. 17). Prosperó la sugerencia del Consulado: el Rey nombró al tinerfeño agente de Canarias cerca de la Corte británica, o "encargado de negocios mercantiles en Gran Bretaña".

Ya era hora de que las autoridades reconocieran sus méritos y su desinterés porque a la sazón el hijo de la Orotava, que tenía 40 años, parecía estar a la cuarta pregunta. D. Francisco Caballero Sarmiento, que le trató entonces, habla "de la miseria en que Lugo estaba sumido en Londres" y le acusa explícitamente de haber vivido de gorrón: "cuando su tío Pepe, escribe a Sebastián de Lugo, sobrino de D. José, se hallaba en Londres viviendo a expensas de sus amigos y haciendo de garante principal en el club de los Jacobinos..." (Demerson, 1988b; se me antoja que el Club de los Jacobinos que denuncia Caballero Sarmiento podría ser el Club Hispanus, del que se hablará más adelante) arrastraba tras de sí crecidas deudas.

Fuera de esos apuros financieros que nos revela la correspondencia del Sr. Caballero Sarmiento, no sabemos nada de la vida que hacía el canario en la capital inglesa durante la Revolución francesa. Afortunadamente, otro español, madrileño por más señas, acertó a pasar entonces casi un año entero en esa Corte, desde el 27 de agosto de 1792 hasta el 9 de agosto de 1793. Este español, viajero curioso y "escribidor" impenitente, no era sino D. Leandro Fernández de Moratín, bien conocido en la capital de las Españas como poeta, luego comediógrafo y más tarde como el historiador del teatro español.

Ahora bien, tenía por costumbre Moratín — cosa poco frecuente entre sus compatriotas en esa época- escribir un diario en que iba consiguiendo lo que le ocurría cada día. Pero ese diario suyo no se parecía al que por los mismos años escribía D. Gaspar Melchor de Jovellanos. El asturiano apuntaba en castellano y en prosa corriente las principales cosas que hacía, las personas con que alternaba, las obras que leía o que se leían en su tertulia de Gijón, los proyectos que se proponía realizar, las noticias importantes que llegaban de la Corte o del país, etc. Algo parecido hacía por supuesto D. Leandro; pero concebía sobre todo ese diario como una especie de recordatorio muy personal, hasta confidencial. Por lo cual procuró conferirle un carácter esotérico, incluso secreto, con el fin de hacerlo incomprensible a los lectores eventuales. Varios contemporáneos suyos, como Cadalso y Meléndez Valdés, al perseguir el 
mismo fin de ocultar a veces algo que se escribían, usaron de una clave, de un lenguaje en clave (Demerson 1985). Moratín por su parte, adoptó otro método, el que su padre, Nicolás Fernández de Moratín, había usado en su diario. Leandro, pues, al heredar los papeles de su padre se limitó a seguir el ejemplo y el método paternales.

Empleaba palabras procedentes de cinco idiomas: latín, español, francés, inglés e italiano. Pero para dificultar aún más la interpretación de esa jerigonza o mezcolanza europea, abreviaba drásticamente, hasta reducirlas a dos o tres letras, a menudo consonantes, los vocablos de ese extraño cóctel, como se ve en el ejemplo siguiente:

\section{9.ch. ti.A. Fnt./ Fnt. Comª .2. Fnt. Me Mal.'}

Con paciencia y perspicacia admirables René y Mireille Andioc consiguieron descifrar ese jeroglífico y hacerlo totalmente inteligible. Y como el Diario de Moratín abarca casi 28 años, desde enero de 1780 hasta marzo de 1808 (con algunas lagunas importantes), el lector comprenderá el interés de ese documento extraordinariamente original que contiene un sinfín de informaciones y juicios sobre personas y acontecimientos de esos casi tres decenios, y en particular sobre el mismo autor que, creyéndose totalmente amparado y protegido por la clave que se había forjado, apunta confidencias y secretos que nunca jamás hubiera revelado voluntariamente.

1. Fernández de Moratín, 1967, 9 de diciembre de 1781, pág. 52.

El baturrillo lexicográfico usado por Moratín merece unas líneas.

El latín proporciona a Moratín, que parece dominarlo aunque lo aprendió solo, muchos verbos sobre todo en primera persona del pretérito perfecto - cosa lógica en un diario--: vidi, inveni, vidimus, risimus... El madrileño duplica a veces en este tiempo la consonante final del radical: lussimus (de ludere, lusi), futtui (de futere), etc. Además toma prestado del latín numerosas preposiciones o adverbios: cum, in, ex, ubi, usque, ad, super y cierto número de pronombres, sustantivos o adjetivos.

Del francés toma: il, ici, chez, manger, ambassadeur, nouvelle (noticia), promenade, returner (sic), voyage, Don Jacques (por Santiago), etc. dinero...

Del español, no rehuye usar palabras comunes: calles, libros, libreros, tragedia, gruñimiento,

Del inglés: house, mother, street (doble de casa, madre, calle), etc., que se encuentran también en el Diario. Sin embargo, por regla general, la elección que hace de un vocablo el autor es definitiva.

Al italiano toma prestados scherzi, notizia, etc. Son más frecuentes los italianismos después de 1793 cuando reside durante varios años en la península.

Algunos ejemplos, recogidos al azar, de la mezcla lexicográfica que compone el Diario:

Notizia ex declaratio belli ex Galicia (sic: Galia) ad Spain (marzo 1793).

Risi, nam il disputa cum French.

Reda, éxilé 8 days avant, madre plorans.

Ego seul in Strand manger.

Cum Lugo por chocolatero usque ad Bourse, ego despeado.

Cum Sames, chez Madame Barens, pictora danesa, vidi tableaux de fleurs.

La técnica de Moratín consiste en yuxtaponer palabras de distinta procedencia. Es evidente que no respeta la sintaxis latina: "spectans quaedam meretricula" (20-XI-1804). 
No hay por cierto, ningún secreto en el breve apunte que hemos propuesto como ejemplo. Quiere decir simplemente: "Domingo 9. Chez tía Anita; Fontana. / Fontana; Comedia 2; Fontana. Madre Mala". Esa Fontana, a la cual acudió tres veces en el mismo día Leandro de Moratín, era por supuesto el conocido café de La Fontana de Oro.

Lugo permaneció mucho más tiempo que Moratín en Inglaterra. Estaba ya en Londres, donde llevaba cuatro años cuando, el 27 de agosto de 1792, llegó a esa capital el futuro comediógrafo, provisto de una pensión que le había concedido Godoy; y el canario había de permanecer allí otros tres años - hasta 1796- después de la partida de D. Leandro, que tuvo lugar el 9 de agosto de 1793. Durante ese año no cabal que el futuro autor de El sí de las niñas pasó a orillas del Támesis, los dos compatriotas se encontaron y trataron a menudo: a veces sólo durante un almuerzo; a veces durante una tarde, otras durante un día entero, "hasta las 12 de la noche" como en una ocasión queda apuntado en el Diario. Incluso hicieron juntos y con otros compañeros una excursión a Southampton que duró 12 días, tiempo suficiente en verdad para que cada uno hiciese amplia cosecha de recuerdos en los que estaban mezclados los otros.

Salvo error u omisión, los nombres de los dos hombres, Lugo y Moratín, aparecen juntos en el Diario 46 veces, cifra que por sí sola manifiesta indudable compañerismo y hasta cierta intimidad. Llevaba ya mes y medio Moratín en la capital inglesa cuando se encontró por primera vez con Lugo, el 15 de octubre de 1792. Creo que no se conocían aún. Tomaron café juntos. Dos semanas después, el día 1 de noviembre, almuerzan el uno y el otro en casa del embajador español, invitación que el anfitrión, Marqués del Campo, rumboso, les repetiría en varias ocasiones. El 11 del mismo mes, ambos participan en otro almuerzo, pero esta vez, el que recibe es el Cónsul General de España, D. Manuel de las Heras, quien invitará varias veces más a éstos y otros compatriotas suyos.

Si bien Lugo fue para Moratín un acompañante frecuente, hubo otro español que lo fue podríamos decir que constante: Carlos Gimbernat (1764-1834) que se dio a conocer más tarde como geólogo, geógrafo, químico, "termalista" —valga la palabra - y autor de varios tratados científicos en francés, español y alemán ${ }^{2}$. Pero en 1792, a los 24 años, Gimbernat no pasaba de ser, al igual que don Leandro, un simple becario del gobierno español: el año anterior, le habían concedido una pensión para estudiar en el extranjero, concretamente en Gran Bretaña.

2. Gimbernat trabajó también para los soberanos de Baviera. Estudió los vapores del Vesubio, y trató de aprovecharlos para obtener agua condensándolos, y también para curar ciertas afecciones. 
Entre el 11 de octubre de 1792, en que sale por primera vez su nombre en el Diario y el día 9 de junio de 1793 en que desaparece, es decir en un período de ocho meses, el nombre de Gimbernat queda apuntado, salvo error, 272 veces en el cuadernillo del madrileño. Ciertos días, se va repitiendo hasta tres veces: así, el domingo 11 de noviembre de 1792: "Chez Gimbernat, breakfast; cum Lugo chez cónsul; cum il y Gimbernat in Strand Caféhouse manger. Calles. Gimbernat ici" (P. 90).

Y conste que en el anterior cálculo, sólo tuve en cuenta los casos en que aparece en el Diario el apellido de Gimbernat con todas sus letras; pero si contáramos las veces en que está representado por "il" ( o sea "él" en castellano) la cifra sería mucho más elevada.

El trato del comediógrafo y del geólogo fue tan continuo, tan constante que los dos hombres, que solían salir juntos de noche, al terminarse su trasnocho se quedaban a dormir ambos en aquella casa que les resultaba más cercana: o la de Moratín o la del catalán. Gimbernat y Moratín eran en Londres no digo como mellizos, pero sí como hermanos siameses. $\mathrm{Y}$ ese comportamiento se explica sin duda por la identidad de su situación social y económica: la de pensionados del gobierno español. Libres de sus movimientos, podían ocupar su tiempo a su antojo. Y Lugo, que tenía que ganarse la vida, sólo se juntaba con ellos cuando lo podía.

Entonces los tres hombres solían comer juntos, salir a callejear o a pasearse por la ciudad: se les veía en el parque Saint-James, en Hyde Park, en diferentes barrios londinenses. En ocasiones, capitaneados por Moratín, que era como todos sabemos un entusiasta de las representaciones teatrales, iban a la Comedia de Hay Market, el teatro de Covent Garden, el único aceptable en opinión del madrileño, al Templo de Flora, "risible spectacle", al Royal Circus donde se daba "una pantomima pestilente!". Por fortuna, en Hay Market se representaban a veces tragedias en que era protagonista la actriz Siddons, por quien Moratín sentía una profunda admiración: la juzga "optime" en uno de sus papeles. Ocurrió que los tres compadres entrasen en un baile popular; pero no tardaron en salir...

Por el Diario nos enteramos de los establecimientos adonde iban a almorzar (nunca se habla de cena): la Hostería de la calle Oxford, la Strand Café House, el Café près Saint Martin (sic), el Café de Orange, the Crown and Ancre Tavern, the Oxford Tavern... También comen en el Sablonière, restaurante francés a cuyo dueño había conocido Moratín en París.

Otros días, sus salidas tienen un fin que hoy día diríamos más "cultural" que gastronómico; visitan el Museum Britanicum, o van "a videre Rinozeros" (sic). De Westminster hacen una visita detenida y asimismo de Saint-Paul 
Church. Otra vez, van "a videre linterna mágica". Ocurre que las excursiones sean de mayor envergadura: del 7 al 10 de mayo, Moratín apunta: "Cum Lugo, ad mar, in Southampton”. En el verano de 1793, se bañan en el Támesis...

Uno de los sitios en que solían reunirse los españoles residentes en Londres era el Club Hispanus, especie de peña nacional, organizado sobre el modelo de los clubs ingleses, en que los socios se reunían los jueves para comer, beber y sobre todo discutir y discurrir de todo lo opinable. Encargado Moratín de componer los estatutos del Club, por haber sido anteriormente nombrado Secretario de la Comisión correspondiente (15-XI-1792), el madrileño revela insospechados dotes de organizador, pues la semana siguiente presenta el fruto de sus meditaciones: "Cum Lugo, legi ad Comisión estatutos, placuerunt". Placuerunt, sí, pero no a todo el mundo, pues el 27-XI nota D. Leandro: "Cum Lugo y Gimbernat Chez Sames: disputas super estatutos". Es que el asunto no carecía de importancia: los estatutos de la nueva entidad habían de someterse a la aprobación de las autoridades británicas. A pesar del satisfecit que en un principio algunos dieron al secretario, había descontentos: "Gruñimientos de Nava y Cadalso ${ }^{3}$ propter lista envoyée ad Ministro" (14-2-93). En esas reuniones del Club, se propalaban noticias locales o generales, y el canario no es el último en traer nuevas: "Lugo dixit insurrección ex Marins Turtlintes" (17-2-93). Otras veces, las discusiones eran filológicas: "Club Hispanus: disputavi cum Gimbernat super dialectus catalaunicus" (es decir, sobre el catalán) (20-12-92).

Así y todo, la "cuestión palpitante" del Club Hispanicus no queda zanjada y vuelve a surgir periódicamente, como hoy día la de la existencia del monstruo del Loch Ness: "Nueva lectura y discusión de los estatutos" el 6 de diciembre de 1792. El 7 de febrero de 1793, ¡Albricias! se enteran los socios de la "aprobatio Regis ad Estatutos ex Club". Pero el 25 de abril, se produce otro incidente: "Club Hispanus. Cum Gimbernat. Magna disputatio cum Lugo. Legí actas del 4 y 11 , reformas in hora".

Sin más problemas que la vidriosa puesta a punto de los estatutos del Club, la vida corría agradable para los dos pensionados del gobierno español. Vivían a su aire, ningún interventor venía a fiscalizar el uso que hacían de las cantidades que les abonaba el Erario. Podían emplear su tiempo como Dios, o el Diablo - personalmente, en ocasiones, apostaría por el Diablo- les daba a entender, y nadie les impedía hacer de su capa un sayo, e incluso quitarse el sayo.

En efecto, además de las visitas que llamaríamos hoy en día turísticas a los monumentos de la capital británica, o de las visitas de cortesía —o interesadas-

3. Primo o sobrino del autor de las Cartas marruecas. Véase Cadalso, 1979, págs. 178-182. 
a personalidades o amigos, se ve en el Diario que Moratín y su cómplice llamaban con alguna frecuencia a la puerta de ciertas casas hospitalarias en que moraban unas señoritas acogedoras y moderadamente recatadas con las cuales les gustaba alternar.

Aunque su biógrafo Silvela dice que D. Leandro era "sobrio en los placeres"; aunque Hartzenbuch, al publicar sus Cartas, expurga púdicamente, tijeras en mano, su correspondencia, sabemos tanto por el Diario como por el copioso y sabroso epistolario de Moratín que conserva la Biblioteca Nacional de Madrid y que René Andioc publicó in extenso, que Moratín no vivía exactamente como un ermitaño. Si bien cobraba las rentas - modestas- de un beneficio eclesiástico; si, en los días de precepto iba a misa, hecho que consigna en sus apuntes, eso no le impide dejarse llevar por la sensualidad, que al parecer tiene muy viva. "Sus relaciones en Madrid con "la Mahonesa" -cuyo nombre aparece a menudo al principio del Diario - no tienen nada de platónico" escriben R. y M. Andioc (pág. 19 de su edición) ${ }^{4}$. Y cuando viaja, D. Leandro busca y halla sustitutas a la Mahonesa. En los dos meses que pasa en Burdeos (19 de mayo a 19 de julio de 1792) va dieciséis veces "chez catins", "chez putas", "chez quaedam meretrix"; incluso participa con su amigo Chabaneau en una orgía con dos mujeres, según confesión propia: "Orgie; illa alteraque nudae lussimis".

Del 25 de julio al 20 de agosto, reside en París; y en la capital francesa, cuyo populacho se entrega a sus instintos sanguinarios, Moratín sólo experimenta una emoción, fuerte por cierto, que arrolla todas las demás y todos los deseos: el miedo, un miedo pánico: "Ego pavor; ... têtes in lanzas, pavor". Emoción violenta que perdudará por otros motivos, durante la travesía del Canal de la Mancha: "Embarquéme in Paquebot, pavor terribilis" (26 de agosto de 1792).

Pero en la paz de Londres, ciudad civilizada, donde la gente no solía pasear cabezas cortadas al extremo de unas lanzas, lejos ya de las salvajadas revolucionarias, recobra la serenidad, y con ella la cachondez, y reanuda sus visitas a las heteras, visitas que va apuntando conscienzudamente, como acostumbra. Mas, - ¿será secuela del pánico que le causó el Terror, o consecuencia del "frigus" londinense que varias veces denuncia, o efecto de una baja de vitalidad? - en casi un año que pasó en Londres, solamente dieciocho veces alude a esas señoras, cifra muy baja comparada con las noventa visitas o más que el ritmo de su actividad en Burdeos parecía pronosticar. Y por si esto fuera poco, el madrileño se contentaba a veces con hablar con esas pelanduscas: "putas loqui", sin duda para mejorar su inglés!

4. En efecto, véase el 10-IV-1792: "Chez Mahonesa, futtui; optime”. (pág. 78). 
A menudo, en esas expediciones, le acompañaba Gimbernat, quien conservaba su libertad de acción: cierto día Moratín se contenta con beber: "ego vinum"; pero su compañero se queda "ad futtutionem" (sic). Al parecer, José de Lugo no participaba en esas bacanales. Sólo en una ocasión el nombre del canario está asociado al del madrileño y al del catalán. Pero en realidad se trata de una expedición frustrada, el 23 de noviembre de 1792: "Chez Gimbernat, cum il, Lugo, etc. in Sablonière manger; cum ils, in coche, buscar quaedam meretrix, sed non invenimus; café; cum il in Queen Street, bayle meretricio, sed horridae". No parece que Lugo acompañara a Moratín en sus múltiples andanzas mujeriles, ni siquiera en alguna de ellas".

Y tuvo razón. Pues el mismo Diario nos recuerda que el trato de esas amables amazonas entrañaba un peligro cierto. Un tal Locktón -o Loctóncomensal ocasional de los dos españoles, acompañó a Moratín y Gimbernat en una de esas salidas. A las pocas semanas, éstos se enteraron de que su compañero de juerga tenía que guardar casa y cama porque padecía lúe venérea, o sea sífilis. Afortunadamente, los galenos londinenses hubieron de hacerle una cura eficaz, puesto que, al cabo de un par de meses, el enfermo ya estaba en la calle y se reunía con sus amigos.

Así, gracias a los detalles que, pacientemente, fue apuntando Leandro de Moratín en su Diario, no incurriremos en el error de imaginar a José de Lugo viviendo solitario y totalmente aislado en medio de los ingleses en la capital británica. El Diario nos revela que existía en Londres durante la Revolución francesa una colonia española relativamente numerosa, activa, incluso algo bulliciosa, cuyos componentes se ocupaban afanosamente de sus negocios, como lo hacía el propio Lugo. Esos españoles, diplomáticos o comerciantes, pensionados por el gobierno español o estudiantes, intelectuales o artesanos, que debían de hablar inglés más o menos de corrido, participaban en la vida social inglesa, frecuentaban los restaurantes, los cafés, los lugares de reunión, las salas de fiesta, los espectáculos en boga y otros establecimientos públicos. Gente con algunas preocupaciones turísticas antes de la letra, ávidas de visitar monumentos, museos, puertos, de frecuentar bailes, teatros y demás espectáculos como la "linterna mágica", en una palabra gente deseosa de ver y comprender un país que para ellos era "diferente".

Pero esos visitantes de Inglaterra eran españoles y no se podían desprender ni a veinticinco tirones de su españolidad. Formaban un grupo bullicioso que había traído consigo de la terruña el gusto por las tertulias, las discusiones de sobremesa, las "piñas" o las "peñas", que allí, para sacrificar a la moda local, llamaban "Club"; un grupo que no quería fundirse ni confundirse con los nativos, sino que mantenía viva su diferencia nacional, e incluso, hacía alarde de su calidad de celtíberos y de su españolismo. Una sociedad en suma que 
prefiguraba ya la que formarían un cuarto de siglo más tarde los liberales españoles exiliados, sociedad que describiría con talento en Liberales y Románticos el profesor Vicente Llorens.

\section{BIBLIOGRAFÍA}

CADALSO, José. 1979. Epistolario, ed. Nigel GLENDINNING, Londres, Tamesis.

DEMERSON, Jorge. 1985. "Cadalso y el secreto". Coloquio Internacional sobre José Cadalso (Bolonia Oct. 1982), Abano Terme, Piòvan, págs. 79-104.

- 1988a. Un diplomático y hombre de negocios canario, D. José de Lugo-Viña, La Laguna, Instituto Estudios Canarios, págs. 13-16.

—. 1988b. "un diplomático canario pionero de la lexicografía provincial: Sebastián de Lugo-Viña y Massieu", Anales de Literatura Española VI, págs. 181-203.

FERNÁNDEZ DE MORATÍN, Leandro. 1967. Diario, ed. René \& Mireille ANDIOC, Madrid, Castalia. 